\title{
The Study of Supporting Elements in Small Towns' Urbanization with Characteristics
}

\author{
Jian Zhang ${ }^{1}$, Yujin $\mathbf{L i}^{2}$ \\ ${ }^{1}$ College of Architecture and Urban Planning, Tongji University, 1239 Siping Road, Yangpu District, Shanghai, P.R.C.. \\ ${ }^{2}$ College of Management, Shanghai University of International Business and Economics, 1600 Wenxiang Road, Songjiang \\ District, Shanghai, P.R.C.. \\ tongjizhangjian@vip.sina.com, liyujin1011@126.com
}

\begin{abstract}
To get a further knowledge over the essential characteristics supporting small towns' urbanization process, case study utilizing towns in a abroad China was conducted. Theme features were discovered to be related to humanistic spirit, historic feature, particular industry and market-oriented strategy. The key elements lie in well reserved and planned architectures, squares, parks, rivers and transport networks.
\end{abstract}

Index Terms - Small towns, Urbanizatio, Characteristics, Theme elements, Key elements

\section{Introduction}

Though the town is a basic governmental unit in many countries, the detailed definition varies with locations and time. In China, the concepts of small towns, cities and towns have experienced a complicated process and shown distinctive characteristics in different historical periods [1]. In July 2000, the CPC Central Committee along with the State Council promulgated the "opinions on promoting several small towns to develop in the healthy way ", clearly giving a clear definition of "small town": state-approved towns, including the county government resident and other towns. In general, small towns facilitates between urban and rural region, leading the development of rural areas, and serving as a necessary supplement the city's equipment. It's well considered that the development of small towns grants us a critical way of urbanization with Chinese characteristics [2]. However, when it comes to urbanization in recent years, we feel worried that China's small cities and towns shared too much in out-look and city planning while lose its own characteristics rapidly. How to build a small town featured in own elements has become a commonly harsh problem. This paper is aimed to describe and contrast domestic feature of small towns, figuring out the key elements in the process of building small towns through summarization though case studies.

\section{Case Study of Small Towns' Urbanization with Bright Characteristics}

\section{A. Xidi, Hongcun in Anhui Province}

Xidi and Hongcun town is the first national historical and cultural village in China. Idyllic paradise-like and well-preserved village form, exquisite and vivid Huizhou-style living all grant this town with attractive tourism resources. In the historic development, unique plains, rivers and mountains are made in harmony with surrounding villages. What is rare, more than 300 buildings which were built in Ming and Qing Dynasty have been well-preserved. These architectures display exquisite carvings, wood, brick and stone with a high artistic value, all of which are in much value. Nowadays, Hongcun is re-planning and optimizing the construction of modern service area. It aims to protect the surrounding bucolic village in the state of aboriginal life. The local government spares no effort to thriving this historic town through protection, inheriting though development. The goal is to enable Hongcun develop into a community-based, world cultural heritage tourism demonstration area, which is combined with heritage protection, residential tourism, cultural experiences, and life leisure.

\section{B. Yiwu in Zhejiang Province}

Zhejiang is a province of the mature market system, and develops towards spatially concentrated and structurally optimized mode. Located in the middle area of Zhejiang Province, Yiwu proposes "to develop industry with booming business, mutual promotion between industry and business". As the very characteristic of Yiwu, small commodity market plays a vital role the rapid growth of industrial economy, while also stimulates the economic development in relevant region. At the begging of Yiwu's growth, it benefits a lot from the "Wenzhou mode" and shares many same points in economy structure. With consecutive exploring, it gradually forms a unique Yiwu economic development path, which thanks to extended market order, benign tissue growth, optimized professional transportation and healthy interaction of industrial cluster development.

\section{Tingxi in Fujian Province}

Tingxi Town, located in Xiamen City, Fujian Province, an area of 155.85 square kilometers, has jurisdiction over 13 administrative villages, population 19,000 , is a typical mountain town, the old towns. Tingxi pleasant climate, beautiful scenery, old times, rich, good ecological environment and superior natural resources, is an important advantage Tingxi economic development.

Tingxi enjoys abundant geothermal resources, based on which "bent wings of a core" overall plan is put forward. In detail, the "core" denotes creating "spa capital", the "east wing" is a bucolic, rural farmhouse based tourism. Meanwhile, the "west wing" points to weak-kneed historical relics, which includes Ding village leisure clubs as the biggest selling point. The scenic mountains, lakes, valleys all constitute the fascinating ecological charm of Yunding mountain. Green 
Road, Ocean Street, local spa and cuisines are considered as significant elements of Tingxi Town.

Analyzing the development of other small towns and drawing comparison of domestic and international experience, Tingxi Town resists the temptation of industry. It is dedicated to explore the unique "structure-leapfrog development" and "Tingxi mode". Based on the traditional agricultural economy, Tingxi skips industrial stage of economic development, has an access to a green economy stage directly.

\section{Kalundborg in Denmark}

Seated in the western Zealand in Denmark, Kalundborg is a small industrial city with only 20,000 inhabitants. Granted with the natural deep-water ice-free harbor, many large enterprises have settled down here. In the late 1960s, major companies in Kalundborg shared the exchanges of steam, different temperatures and purity of water and a variety of by-products or waste. Since the 1980s, the local development sector gradually realized and spontaneously created a system, which is called "industrial symbiosis". With consecutive development, its size along with influence grew, turning to be a circular economy with the implementation of the traditional model, known as the "Kalundborg mode". In detail, many companies combined the establishment of industrial ecological chain relationships and metabolic derivative through the joint use of resources to improve the efficient use of resources. It ultimately achieves pollution system "zero emissions" with the primary motivation to reduce cost. Nowadays, Kalundborg Industrial Park is the most typical industrial ecosystem in the world. With the enterprises including power plants, refineries, and gypsum board manufacturing plant as the cores and through the use of trade waste or by-products generated during the production of each other, it produce good economic returns, as their cheap production of raw materials, consequently enabling economic development and environmental protection conducted in a virtuous cycle.

\section{Analysis of the Significant Elements Supporting Small Towns' Urbanization}

\section{A. Theme elements}

In consensus, urbanization is considered as the result of economic and social development, among which construction of small towns constitutes as a significant part [3]. The urbanization process started earlier in western countries. In order to narrow the economic gap between urban and rural areas, governments conducted a series of implementation to benefit the development of small towns. It gradually formed a geographical division of labor pattern. Since the reform and opening up in 1970s, small towns in China have been rapidly re-constructed and developed. Phenomenally, 1980s witnessed the acute increasing number of towns with bigger scale. It is concluded by studies afore that the vast majority of China's small towns are historically formed spontaneously with some natural rationality [4]. Hence there are some imbalances and blindness existing in the urbanizing process of small towns in this country. Due to temporal and spatial differences actually exist with particular history, geography and economic conditions, the complicated urbanization process in China shows prominent characteristics. The authors would like to discuss several common points in the remainder of this paper.

Primarily, the humanistic theme is essential. Humanistic elements are comprised of historical figures, monuments, folk customs, folk art, which are unique and inimitable for small towns respectively. China's small towns enjoy profound cultural and historical features, and could further their values through brilliant mining. For instance, Hongcun Town distincts itself by architecture and merchant culture. Fujian vulgar culture is featured with elements of urban construction.

Historical theme is necessary. It is no exaggeration to say that protection of cultural and historical heritage, is closely related with economic and social development. When the small town's traditional culture is well inherited and reserved, the cultural quality of small towns is enhanced. In consequence, the tourism industry gets booming and to make the rich cultural traditions become "financial resources" in return. Generally, traditional features are formed from two aspects, one is about the mining historical context, inheriting the fine traditions and cultural heritage; the other lies in the traditional cultural background, with which a new culture in a flavor of the times can be created.

Specialized industries with own characteristics are of great value. Taking advantages of local resources, location and transportation advantages, small towns should operate the strategies according to local conditions. For example, Hongcun tourism, eco-leisure industry in Tingxi Town all combined the local natural, cultural and traditional with protecting the ecological environment. Consequently, the development of urban economy is quite smooth and sound.

Market-oriented strategy is also encouraged. It's wise to comply with domestic and international market demand, adjust the industrial structure of small towns and establish regional division of labor cooperation mechanism. Zhejiang Yiwu Small Commodity Market is a vivid model of gathering development. Driven by the market, the rapid growth of the industrial economy, the formation of small towns with prominent features can be realized.

\section{B. Key elements}

Previously, researchers have suggested that the identified components of the city including: physical environmental appearance, particular events and gatherings, as well as the meaning or symbolism [5]. It should cover natural and artificial elements in addition to humanistic ones. Although the functions and scales of the small towns present to be different from the city, the same lies in constituent elements. Numerous factors determine the characteristics of small towns: social, economic, cultural, historical and natural conditions. These result in various characteristics for each town. From the case study, we can clearly see some of the success points with common features, which display the key elements supporting small towns' urbanization.

1)Transport network: This network functions as the crucial element for urbanization. Roads with green space system are essential parts of urban space image, ascending the spatial quality of urban life [6]. Meanwhile, urban roads 
should facilitate a structural ingredient of the small town, better building a relationship among other elements, reflecting spatial order and expressing characteristics of urban landscapes.

2) Square: as a human social activity place, square space system shapes an unparalleled carrier of cultural heritage. Therefore, the design of the square should meet the person's need and support for meaningful social activities. Spiritual and material factors should constitute plaza space, reflecting its comprehensive attractiveness.

3) Architecture: it's the most intuitive image reflecting the small town's style. Local characteristics of traditional houses are formed with working people's effort to create a home environment, following the laws of nature. Usually, they are close to nature and in favor of ecological balance, presenting a strong local style while lacking personality compared to reinforced concrete construction [2]. Urban residents have shown a growing interest on local traditional architecture and culture. Hence excellent ideas and practices have sprung up in the newly-urbanization process. This trend inherits traditional residential architecture, abandoning passive components in the use of modern materials and technology. Additionally, development and innovation enable the small towns with rapid development well reserve local characteristics, residential buildings and traditional residential architecture throughout.

4) Rivers: this network inside the town is regarded as an interpretation of the urban landscape form, industrial and styled characteristics in addition to space structure. Roads, water, green plants and other combinations, with the integration features, all demonstrate the town features.
5) Park: the town as a public space, the park has a sense of urban landscape and structure, spatial organization of social life has played an important role, parks and public buildings, squares and flags, green system, river system echoes reflected the town common the building features.

\section{Conclusion}

In review of several case studies concerning small town's development process, we concluded the significant elements supporting the urbanization with bright characteristics. It is rational and wise for policy-makers to reserve and inherit the own characteristics of small towns. Theme features were discovered to be related to humanistic spirit, historical feature, particular industry and market-oriented strategy. The key elements lie in well reserved and planned architectures, squares, parks, rivers and transport networks. When it comes to urbanization of small towns, primarily, emphasis should be put on these key elements with effort.

\section{References}

[1] Antrop, M. (2004). Landscape change and the urbanization process in Europe. Landscape and urban planning, 67(1), 9-26.

[2] Yang, S., Wang, M. Y., \& Wang, C. (2012). Revisiting and rethinking regional urbanization in Changjiang River Delta, China. Chinese Geographical Science, 22(5), 617-625.

[3] Lin, G. (2002). The growth and structural change of Chinese cities: a contextual and geographic analysis. Cities, 19(5), 299-316.

[4] Tian Y. P., Yang, X. M., \& Liu, K. Y. (2008). Strategies for the unified development of mass sports in cities and towns in China. Journal of Physical Education, 1, 002.

[5] Chaolin, G. U., Liya, W. U., \& Cook, I. 2012. Progress in research on Chinese urbanization. Frontiers of Architectural Research, 1(2), 101-149.

[6] Ma, R. (1992). The development of small towns and their role in the modernization of China. Urbanizing China, 119-53. 